Nota Cientifica

\title{
EFEITO DO EPTC + R 25788 EM COMBINAÇÃO COM O DIURON NO CONTROLE DE PLANTAS DANINHAS E SELETIVIDADE PARA A CULTURA DA BATATA-DOCE ${ }^{1}$
}

MAURÍLIO F. de OLIVEIRA ${ }^{2}$,LINO R. FERREIRA ${ }^{3}$, TOCIO SEDIYAMA e JORGE G. MAGALHÃES ${ }^{4}$

\section{RESUMO}

Com o objetivo de avaliar o efe ito das doses de EPTC + R 25788 combinadas com doses de diuron no controle de plantas daninhas na cultura de batata-doce, realizou-se um ensaio sob condições de campo num Podzólico Vermelho Amarelo, fase terraço, argiloso, com 3,5\% de matéria orgânica. Foram avaliadas quatro doses de EP TC + R 25788 aplicado em pré-plantio incorporado: 0,$0 ; 1,6 ; 3,2$ e 4,8 kg/ha por quatro doses de diuron: 0,$0 ; 0,8 ; 1,2$ e $1,6 \mathrm{~kg} / \mathrm{ha}$, em quatro repetições. O EPTC + R25788 apresentou bom controle das plantas de tiririca quando aplicado nas maiores doses, principalmente na ausência do diuron. As maiores doses de EPTC + R 25788 aplicadas isoladamente, apresentaram significativos aumentos na população de plantas de folhas largas. As maiores doses de diuron promoveram melhor controle das plantas de folhas largas, na presença das maiores doses de EPTC + $R$ 25788. A combinação das maiores doses dos herbicidas não refletiram em maiores produções. A maior produção de batata-doce ocorreu quando se aplicou $6 \mathrm{~L} / \mathrm{ha}$ de Eradicane e 1,32 kg/ha de Karmex 800.

Palavras chave: herbicidas, Ipomoea batatas, tiririca, Cyperus rotundus.

\section{ABSTRACT \\ Weed control in sweet potato}

Four levels of EPTC + R $25788(0.0 ; 1.6$; 3.2 e $4.8 \mathrm{~kg} / \mathrm{ha})$ and diuron $(0.0 ; 0.8 ; 1.2$ and 1.6 $\mathrm{kg} / \mathrm{ha}$ ) with four replications were evaluated in a fatorial field experiment in a Utisol containg 3.5\% organic matter. Better control of nutsedge was obtained with the highest dosage of EPTC $+\mathrm{R}$ 25788, mainly in the absence of diuron. However, when the highest eradicane levels were applied as single treatments there was a marked increase in the broadleaf weed population. The best control of broadleaf weed population was achieved when the highest diuron levels were combined with the highest EPTC + R 25788 levels although this condition have not resulted in highest productions. The greatest sweet potato production was obtained with the combination of $61 /$ ha of Eradicane plus $1.32 \mathrm{~kg} / \mathrm{ha}$ of Karmex 800.

Key Words: herbicide, Ipomoea batatas, nutsedge, Cyperus rotundus.

1Recebido para publicação em 26/08/96 e na forma revisada em 16/09/97.

2Estudante de Doutorado da UENF. CEP 28015 -620. Campos dos Goytacazes-RJ.

3 Professor do Dept. de Fitotecnia da UFV. CEP 36571-000. Viçosa - MG.

4 Téc. de Nível Superior do Dept. Fitotecnia da UFV, CEP 36571-000, Viçosa - MG. 


\section{INTRODUÇÃO}

A batata-doce [Ipomoea batatas (L.) Lam.] é cultivada em todo o território brasileiro, sendo os Estados do Rio Grande do Sul, Paraná, Pernambuco, Santa Catarina, Paraíba, Bahia e Minas Gerais os maiores produtores. A produtividade média obtida no Distrito Federal foi $27 \mathrm{t} / \mathrm{ha}$ para cultivares de 4-5 meses. Entretanto, o rendimento médio nacional tem sido em torno de 9,7 t/ha (Miranda et a/.,1984; Peixoto \& Miranda, 1984 e Miranda et al., 1989).

A batata-doce apresenta um alto valor nu tri ti vo, comparado com outras raízes e tubérculos. O seu conteúdo calórico é quase três vezes mais rico do que a cenoura e uma vez e meia mais rico do que a batata (Miranda et al., 1989).

Entre os diversos fatores que concorrem para uma mai or produtividade, o controle das plantas daninhas é um dos mais importantes. Por se r cultivada em clima quente e úmido a infestação de plantas daninhas é normalmente grande. Deve-se controlar as plantas daninhas até cerca de 60 dias após o plantio, devido ao período em que se inicia a tuberização e a época em que as ramas cobrem o solo, impedindo o desenvolvimento de plantas daninhas (Edmong \& Ammerman, 1971; Folquer, 1978 e Peixoto \& Miranda, 1984).

A eliminação me câni ca das plantas daninhas é muito difícil, devido ao hábi to prostado de crescimento das hastes. O cultivo manual é moroso, caro e imperfeito, pois ao se capinar as partes laterais dos camalhões afasta mse grandes porções de terra, que geralme nte não lhes são devolvidas (Glaze \& Hau, 1986). Devido à escas sez de mão-de-obra rural e aos aumentos das áreas plantadas, o controle químico das plantas daninhas vem aumentando grad ativamente. Há grande defíciência de informações técnicas desse as sunto para as condições brasileiras. Os herbicidas EPTC, metribuzin, diuron, linuron, oxadiazon e ametryne são produtos com potencial para serem utilizados nesta cultura (Oliveira et al., 1990).

Estudos realizados por Freitas et al. (1993), demonstraram que a cultura apresentou boa tolerância ao metribuzin e ao EPTC, onde a aplicação do metribuzin aumentou a produtividade da cultura de batata-doce ao controlar eficientemente as plantas daninhas predominantes no local do ensaio, principalmente quando não foi incorporado ao solo. O EPTC destaca-se no controle de gramíneas e da tiririca (Cyperus spp.) (Almeida \& Rodrigues, 1988). 0 diuron mostrouse também seletivo à cultura da batata-doce (Oliveira et al., 1990), o qual controla eficie ntemente as plantas de folhas largas (Almeida \& Rodrigues, 1988).

A tiririca tem-se tornado sério problema em muitas áreas agrícolas, principalmente em condições de altas temperatura e umidade devido à inexistência de produtos específicos para seu controle. O grau de interferência das plantas daninhas com as culturas está em função das es pécies infestantes, da cul tura estudada, dos fatores edafoclimáticos, densidade da cultura e das in vasoras, entre outros. Por is to, é de suma importância a realização de estudos sobre controle de plantas daninhas em diferentes condições, possibilitan do assim, recomendação de controle das infestantes mais eficiente, nos diferentes locais.

O objetivo deste trabalho foi avaliar a efi ciência do EPTC + R 25788 e do diuron no controle de plantas daninhas, aplicados isolados e em misturas, na cultura da batata-doce, em condições de campo.

\section{MATERIAL E MÉTODOS}

O experimento foi conduzido na área experimental da 'Horta do Fundão' do Departamento de Fitotecnia da Universidade Federal de Viçosa, em solo Podzólico Vermelho 
Amarelo, fase terraço, argiloso com 3,5\% de matéria orgânica.

O delineamento experimental adotado foi o de blocos ao acaso, com quatro repetições, no esquema fatorial $4 \times 4$, sendo o primeiro fator as doses de EPTC + R 25788 (0: 1,6; 3,2 e 4,8 $\mathrm{kg} / \mathrm{ha}$ ), marca comercial Eradicane e, o segundo as doses de diuron $(0,0 ; 0,8 ; 1,2$ e $1,6 \mathrm{~kg} / \mathrm{ha})$, marca comercial Karmex 800, além da testemunha capinada.

Após o preparo do solo, aplicou-se o Eradicane com imediata incorporação. Nas parcelas de $4 \times 4 \mathrm{~m}$, foram feitos 4 sulcos de plantio de aproximadamente $10 \mathrm{~cm}$ de profundidade. A distância entre sulcos foi de $1 \mathrm{~m}$ ficando a área útil central com $4 \mathrm{~m}^{2}$. Utilizaram-se ramas da variedade Brazlândia Rosada originárias da $\mathrm{Cl}$ as se 22, BDI $006 \mathrm{CNPH}$. O diuron foi ap licado em pré-emergência, logo após o transplantio das ramas.

Os herbicidas foram aplicados com um pulverizador costal manual, com capacidade de 20 litros provido de uma barra de quatro bicos tipo leque 80.03, regulado para vazão de 300 1/ha.

As irrigações foram feitas por aspersão sendo uma $\log$ o após o plantio das mudas e as demais de acordo com a necessidade. A testemunha foi capinada aos 20, 40 e 60 dias após o plantio (DAP).

Aos 30 DAP foi realizada avaliação visual da fit otoxicidade sobre a cultura, utilizando a escala EWRC (European Weed Research Council), cujos índices de fitotoxicidade nas folhas variavam de 1 a 9 (Frans, 1972). Realizou se uma colheita da matéria verde das plantas daninhas aos 30 e 60 DAP, determinando-se o número e o peso da matéria fresca por espécie. Para as avaliações de plantas daninhas foi utilizado um amostrador de ferro de $50 \times 50 \mathrm{~cm}$, em cada parcela, lançada a $1 \mathrm{~m}$ das extremidades, ao acaso.

A colheita foi realizada aos 145 DAP e as batatas-doces classificadas no seguinte padrão: batatas-doces com menos de $100 \mathrm{~g}$, batatas-doces com 100 a 800 g e batatas-doces com mais de 800 g. O número de plantas daninhas e de raízes de batata-doce foram transformados em 'Ix $+0,5$. Foi calculado o número e o peso de gramíneas e de folhas largas, somando-se os respectivos valores de todas as espécies de cada classe, presentes no ensaio. Calculou-se também o total do número e peso de batatas-doces produzidas.

Foram realizadas as análises de variância e regressão para verificar os efeitos dos tratamentos sobre as plantas daninhas e produção de batatas-doces. Para a escolha entre os modelos lineares e quadráticos foi considerada a significância do teste $\mathrm{F}$, maior $\mathrm{R}^{2}$, desvio da regressão não significativo e lógica biológica.

\section{RESULTADOS E DISCUSSÃO}

As espécies de plantas daninhas predominates no local do ensaio foram: tiririca (Cyperus rotundus), tre vo (Oxalis sp.), capim colchão (Digitaria sanguinalis) e mentruz (Lepidium pseudodidymum).

Não se verificou nenhum grau de fitotoxicidade nas plantas de batata-doce aos 30 DAP.

$\mathrm{O}$ EPTC $+\mathrm{R} 25788$ afetou significativamente o número e o peso das plantas de tiririca $(\mathrm{p}<0,01)$, aos 60 DAP. O diuron afetou significativamente somente o peso de tiririca $(\mathrm{p}<$ $0,01)$, nesta época. A interação entre o Eradicane e diuron não afetou o número e o peso das plantas de tiririca. Na Figura 1, pode-se observar que o número de plantas de tiririca, aos $60 \mathrm{DAP}$, reduziu acentuadamente com o aumento da dose de Eradicane, na ausência de Karmex. O mesmo aconteceu na presença de Karmex. Entretanto, neste caso, tanto o estande inicial e final de tiririca apresentaram-se maiores em relação ao uso de Eradicane isoladamente. Isto se deve ao aumento linear da população de tiririca, qua ndo se usa Karmex, devido ao bom controle que este exerce sobre as plantas de fol has largas, propiciando melhores condições de desenvolvimento da tiririca. $\mathrm{O}$ menor número de plantas de tiririca 


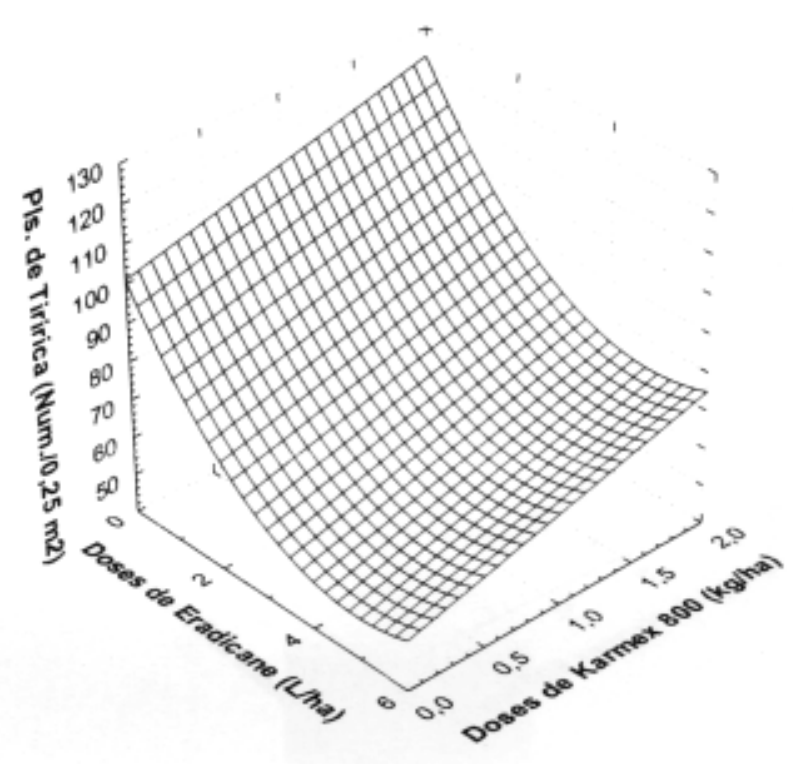

$$
\hat{\mathrm{Y}}=100,909-20,4984 \cdot \mathrm{DE}+10,8893 \cdot \mathrm{DK}+2,0898 \cdot \mathrm{DE}^{2} \mathrm{R}^{2}=0,69
$$

FIGURA 1. Número de plantas de tiririca em $0,25 \mathrm{~m}^{2}$, em função das doses de Eradicane (DE) e Karmex 800 (Dk), 60 dias após a aplicação.

ocorreu na dose de 5 1/ha de Eradicane, isoladamente.

Quanto ao peso de tiririca (Figura 2) aos 60 DAP, o comportamento apresentou-se muito semelhante ao número de plantas de tiririca. Este fato já era es perado, uma vez que há al ta correlação entre número e peso em ciperáceas, devido à baixa plasticidade morfológica desta espécie.

As doses de Eradicane afetaram somente o número de gramíneas $(p<0,05)$, enquanto as doses de Karmex afetaram o número $(\mathrm{p}<0,01)$ e o peso ( $\mathrm{p}<0,05)$ das gramíneas, aos 60 DAP. Para o número de gramíneas houve interação entre as doses de Eradicane e Karmex aplicadas ( $<<0,01)$. Na Figura 3, pode ser observado que o número de gramíneas diminui line armente com o aumento das doses de Eradicane e Karmex, quando aplicados isoladamente. A interação dos produtos também apresentou bom controle das gramíneas; entretanto, houve um pequeno aumento do número e peso de gramíneas, quando se aplica o Eradicane na maior dose de Karmex. Isto se deve provavelmente ao fato do bom con trole que o EPTC + R 25788 exerceu sobre as ciperáceas retardando sua emergência. Como o diuron não atingiu as sementes sub-superficiais das gramíne as, a velocidade de ge rmi nação e emergência destas foi superior à emergência das ciperáceas, razão desta interação.

$\mathrm{O}$ número e o peso das plantas de folhas largas não for am af etados pelas doses de Eradicane e pela interação entre as doses de Eradicane e Karmex. Somente o peso das plantas de folhas largas foi afetado pelas doses de diuron $(p<0,01)$. Observa-se na Figura 4 que, aos 60 DAP, o Karmex aplicado is ol adamente não apresentou grande controle das folhas largas; 
Efeito do EPTC + R 25788 em combinação com o Diuron no controle de plantas daninhas e seletividade para a cultura da batata-doce.

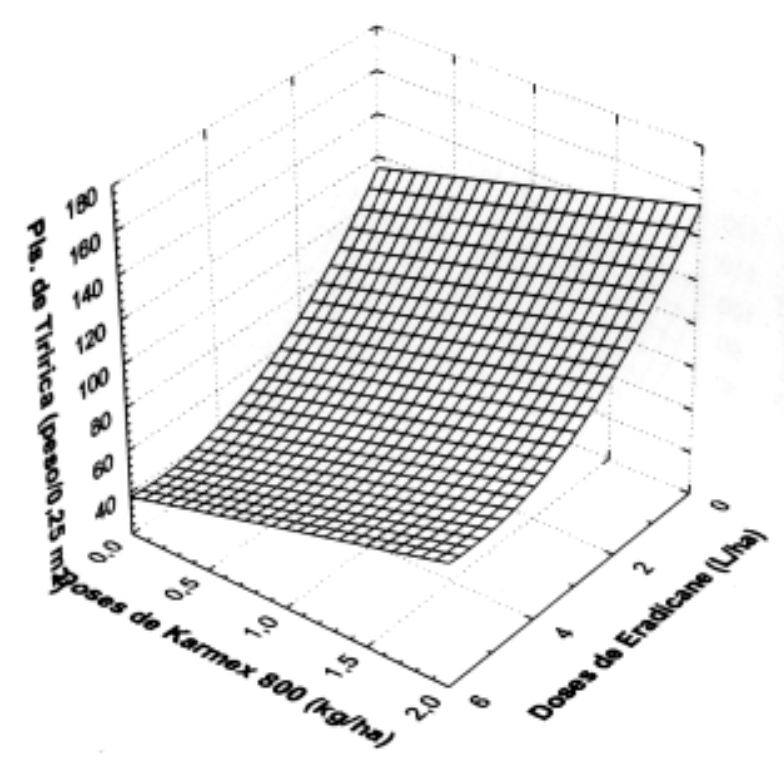

$$
\hat{\mathrm{Y}}=114,531-28,2500 \cdot \mathrm{DE}+19,5000 \cdot \mathrm{DK}+2,5781 \cdot \mathrm{DE}^{2} \mathrm{R}^{2}=0,86
$$

FIGURA 2. Matéria fresca (gramas em $0,25 \mathrm{~m}^{2}$ ) da parte aérea das plantas de tiririca, em função das doses de Eradicane (DE) e Karmex 800 (DK), 60 dias após a aplicação.

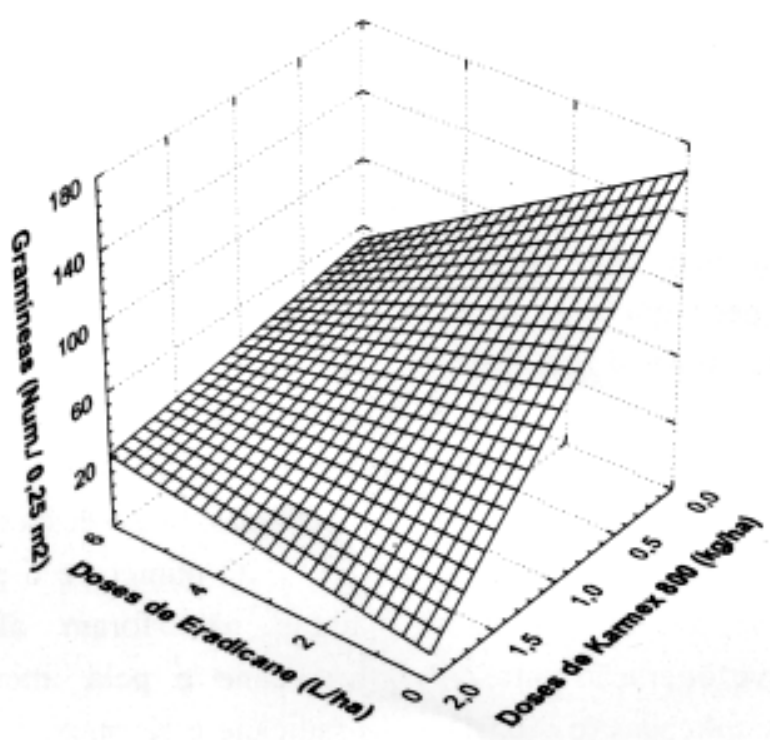

$$
\hat{\mathrm{Y}}=164,606-18,7328 \cdot \mathrm{DE}-84,1827 \cdot \mathrm{DK}+11,5514 \cdot \mathrm{DE} \cdot \mathrm{DK} \mathrm{R}^{2}=0,78
$$

FIGURA 3. Número de gramíneas em $0,25 \mathrm{~m}^{2}$, em função das doses de Eradicane (DE) e Karmex 800 (DK), 60 dias após a aplicação. 


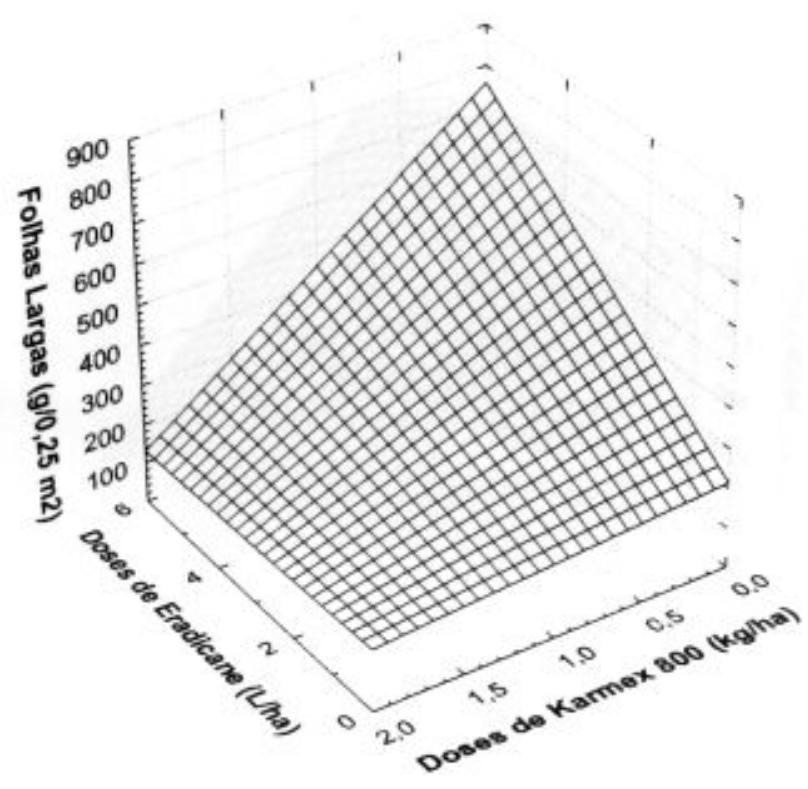

$$
\hat{\mathrm{Y}}=214,649+90,6956 \cdot \mathrm{DE}-28,5543 . \mathrm{DK}-47,6629 \cdot \mathrm{DE} \cdot \mathrm{DK} \mathrm{R}^{2}=0,72
$$

FIGURA 4. Matéria fresca (gramas em $0,25 \mathrm{~m}^{2}$ ) da parte aérea das plantas de folhas largas, em função das doses de Eradicane (DE) e Karmex 800 (DK), 60 dias após a aplicação.

Entretanto, nas maiores doses de Eradicane houve um aumento acentuado na população de dicotiledôneas devido à falta de concorrência das monocotiledôneas. Desta maneira, as maiores doses de diuron evidenciaram melhor controle das plantas de folhas largas.

O número de raízes de batata-doce de 100$800 \mathrm{~g}$ foi afetado pelas doses de EPTC e diuron ( $\mathrm{p}$ $<0,05)$. 0 peso destas raízes não foi afetado pelos herbicidas e nem pela interação dos mesmos. $\mathrm{O}$ número total de raízes de batata-doce foi afetado pelas doses de EPTC ( $p<0,01)$, não se verificando efeito significativo para peso total de raízes para nenhum dos herbicidas avaliados. Como pode-se observar na Figura 5, o número total de raízes de batata-doce aumentou quando se aplicou doses crescentes de Eradicane, combinadas ou não com Karmex. Maior número total de batatas ocorreu na combinação da maior dose do Eradicane $(6$ 1/ha) com aproximadamente, 1,0 $\mathrm{kg} / \mathrm{ha}$ de Karmex 800. Tanto na presença quanto na ausência do Eradicane as maiores doses de diuron reduziram o número total de raízes de batata-doce. Observando a Figura 6, o peso total de raízes de batata-doce não foi influenciado pelo aumento das doses de Eradicane, quando aplicado isoladamente, sendo a diferença de produção entre a testemunha no mato e a maior dose de Eradicane (6 I/ha) pequena. A maior infestação de plantas de folhas largas, devido a ausência de Karmex, foi provavelmente a responsável pela menor produção de batata-doce nesse caso. Portanto, observando o efeito do aumento de doses de Karmex, aplicado isoladamente, na produção de raízes de batatadoce verifica-se que tanto na ausência quanto na pres ença do Eradic ane houve aumento na produção de raízes de batata-doce até a dose próxima de $1,0 \mathrm{~kg} / \mathrm{h}$ a. Nas maiores doses de Karmex 800, assim como ocorreu com o número total de batata-doce verificou-se redução no peso de batata-doce, tanto na ausência quanto na presença do Eradicane. Isto ocorreu devido ao 


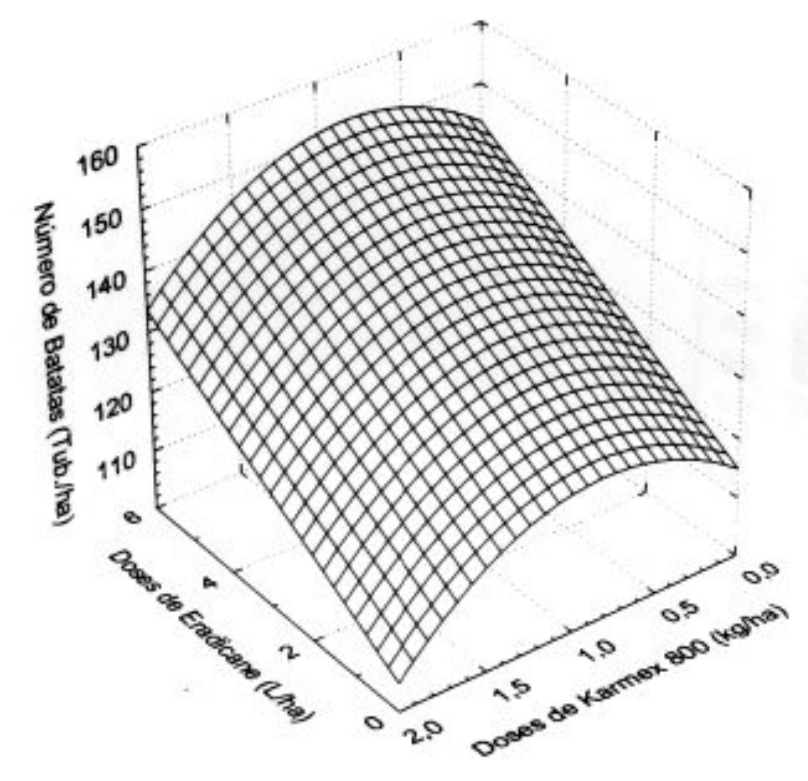

$$
\hat{\mathrm{Y}}=114,986+4,7785 \cdot \mathrm{DE}+21,2959 \cdot \mathrm{DK}-13,1818 \cdot \mathrm{DK}^{2} \mathrm{R}^{2}=0,59
$$

FIGURA 5. Número total de raízes de batata-doce (Tub./ha), em função das doses de Eradicane (DE) e Karmex 800 (DK), 145 dias após a aplicação.

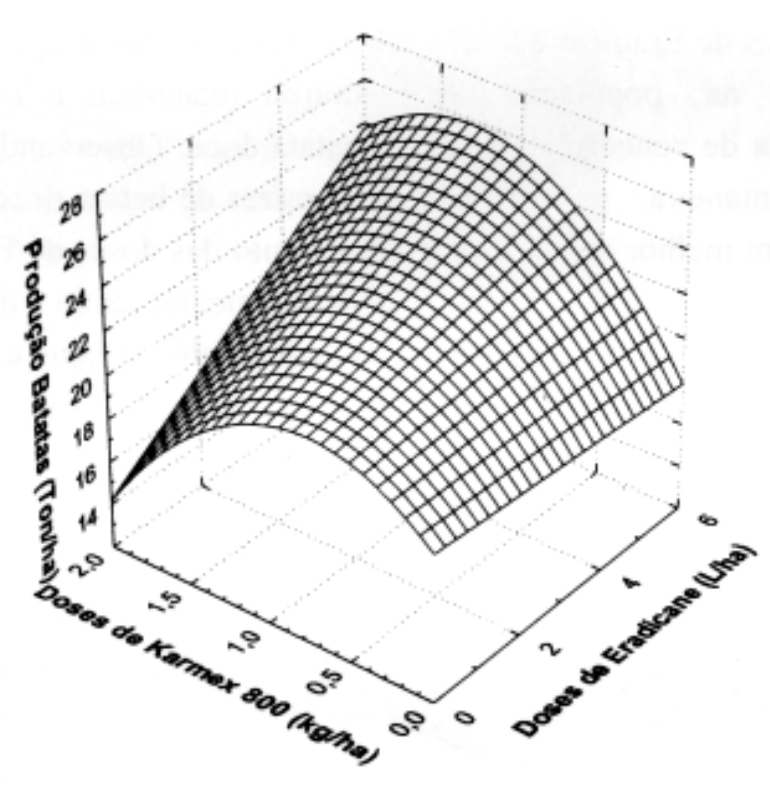

$\hat{\mathrm{Y}}=18,7249-0,1379 \cdot \mathrm{DE}+6,8261 \cdot \mathrm{DK}-4,5485 \cdot \mathrm{DK}^{2}+0,8641 \cdot \mathrm{DE} \cdot \mathrm{DK} \mathrm{R}^{2}=0,68$

FIGURA 6. Peso total de raízes de batata-doce (ton/ha), em função das doses de Eradicane (DE) e Karmex 800 (DK), 145 dias após a aplicação. 
aumento da competição das plantas de tiririca com a cultura da batata-doce. Maiores produções de batata-doce ocorreram na dose de $6 \mathrm{I} /$ ha de Eradicane combinada com 1,32 kg/ha de Karmex 800. Entretanto, verificou-se que, nesse estudo, a combinação das maiores doses dos herbicidas não refletiram em maiores produções, existindo uma faixa de combinação de doses dos dois herbicidas (1,0 a 1,5 kg/ha de Karmex 800 combinada com 4 a $6 \mathrm{I} / \mathrm{ha}$ de Eradicane), que refl etem em produtividades próximas da produtividade máxima.

\section{LITERATURA CITADA}

ALMEIDA, F. S., RODRIGUES, B. N. Guia de Herbicidas. 2.ed. Londrina: IAPAR, 1988. 630p.

EDMONG, J. B., AMMERMAN, G. R. Sweet potatoes; production, processing, marketing; major feed and food crops in agriculture and food series. Westport: Avi., $1971.334 \mathrm{p}$.

FOLQUER, F. La batata (camote). Estudio de la planta y su produccion comercial. San José: IICA, 1978. 144 p.

FRANS, R.E. Measuring plant responses. In: WIL KINSON, R.E. Research method s in weed science. s.1., Southern Weed. Society, 1972.p. 27-41.

FREITAS, S. de P., SILVA, J. F. da. FERREIRA, L. R., SEDIY AMA, T., CCN DÉ, A. R.. Efeito do Eradicane em Combinação com o
Metribuzin, Com e Sem Incorporação, no Controle de Plantas Daninhas na Cultura da Batata-doce. Rev. Ceres, v.40, n.230, p.325333, 1993.

GL AZE, N.C., HA U, M.R. The effects of herbicides on weed control and yield of sweet potato. In: ANNUAL MEETING SOUTHERN WEED SCIENCE, 39, s.1. 1986. Proceedings... s.1., Weed Science Society, 1986. p.172.

MI RA ND A, J. E. C. de, FR ANÇA, F. H., CARRIJO, O. A., SOUSA, A. F., AGUIAR, J. A. E. Cultivo da batata-doce (Ipomoea batatas (L.) Lam.). Brasília: CNPH, 1934. 8 p. (CNPH. Instruções Técnicas, 7).

MI RA ND A, J. E. C. de, FR ANÇA, F. H., CARRIJO, O. A., SOUSA, A. F., PEREIRA, W., LOPES, C. A. Batata-doce (Ipomoea batatas (L.) Lam.). Brasília: CNPH, 1989. $19 \mathrm{p}$.

OLIVEIRA, M. F. de, SEDIYAMA, T., FERRE IRA, L. R. Seleção de herbicidas para a cultura de batata-doce (Ipomoea batatas (L.) Lam.). In: SIMPÓS IO DA PESQUISA NA UFV, 2. Viçosa, 1990. Resumos... Viçosa, UFV, Imprensa Universitária, 1990, p. 202 e 208.

PEIXOTO, N., MIRANDA, J. E. C. de. O cultivo da batata-doce em Goiás. Goiânia: EMGOPA - DDI, 1984. 24 p. (EMGOPA Circular Técnica, 7). 